\title{
The research and development of the automatic solar power tracker
}

\author{
Yan Ping $\mathrm{Li}^{1, \mathrm{a}}$, Zhong Ying Yuan ${ }^{2, b}$ \\ ${ }^{1,2}$ Liaoning Institute of Science and Mechanical Engineering, Liaoning Institute of Science and Engineering Practice Center, 117004 Benxi \\ City, Liaoning Province, China
}

\begin{abstract}
The article describes a kind of automatic tracker using solar power. It depends on two important parts which are servo system and adjusting mechanism system to keep the tracker operating normally. The article focuses on describing the characteristics and functions of two systems and the operating details of the automatic solar power tracker.
\end{abstract}

Keywords: automatic; solar tracking; saturated steam.

\section{Introduction}

The technology of solar power tracking is not only the basis and precondition of using solar power efficiently, but also the supporting element which can improve the solar power equipment' revenue. Nowadays, most existing solar power equipment need external electrical energy to make sure them running normally. Even if some of them have mature solar technology, there still is the limitation of operating locations such as the areas without electrical power; the high alpine areas and so on. So it is necessary to develop a kind of solar automatic tracking device which is economic, practical and safe ${ }^{[1]}$.
$\mathrm{NH}_{3}$ has the certain saturated steam pressure states under the certain temperature which are showed in the table1. when the saturated vapor of $\mathrm{NH}_{3}$ absorbs heat, the temperature and air pressure will rise; if the temperature of the saturated vapor remains unchanged, saturated vapor will be liquefaction and the heat release.

\section{The function of saturated steam pressure of $\mathrm{NH}_{3}$}

\footnotetext{
a Yanping Li: liyanping_1962@,sina.com

b Zhongying Yuan: 1kyyzy@126.com
} 
Table1. $\mathrm{NH}_{3}$ 's saturated vapor pressures and the deviations

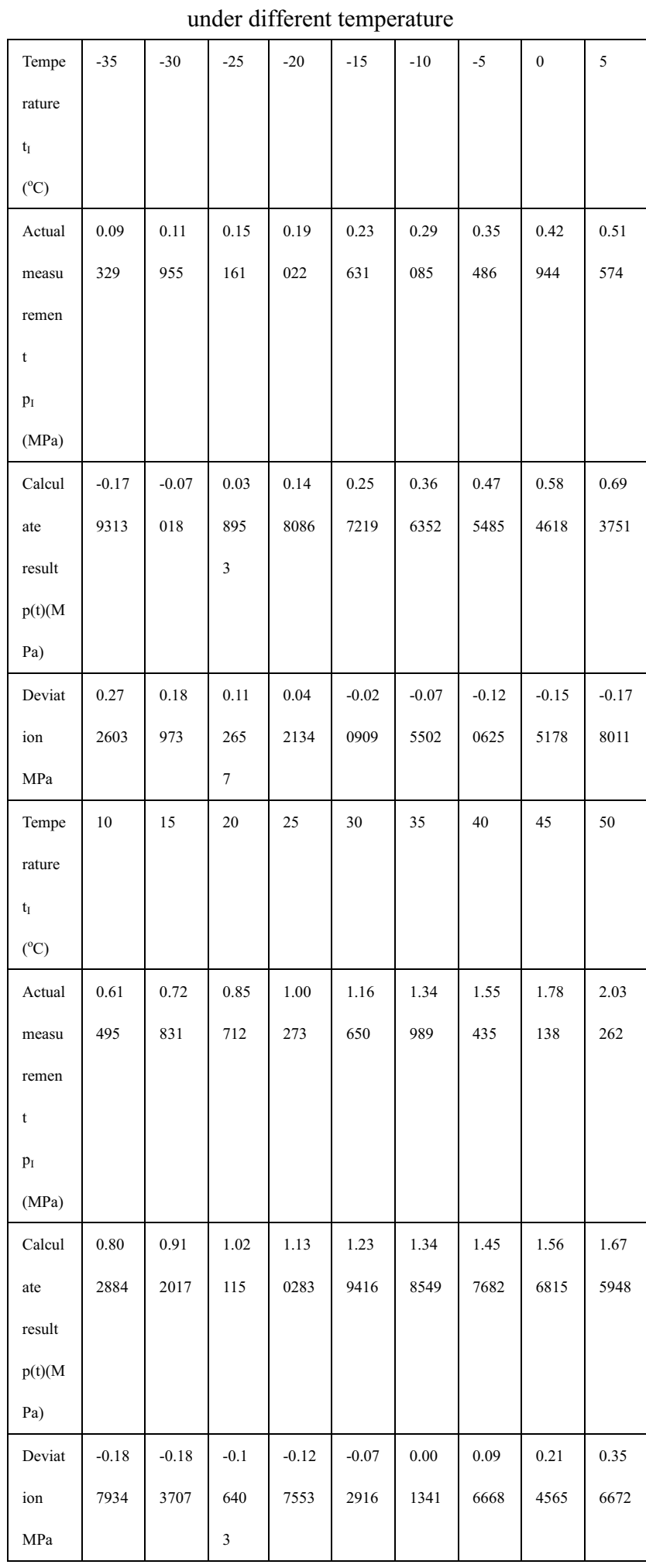

Suppose to there is the linear relation between the saturated vapor of $\mathrm{NH}_{3}$ and the temperature,

$$
\mathrm{p}=\mathrm{at}+\mathrm{b}
$$

, $\mathrm{a}$ and $\mathrm{b}$ are the undetermined constants, so the objective function of least square method:

$$
\mathrm{M}=\sum\left[\mathrm{p}_{\mathrm{I}}\left(\mathrm{at}_{\mathrm{I}}+\mathrm{b}\right)\right]^{2}
$$

,to minimize $\mathrm{M}$, the partial derivative of $\mathrm{a}$ and $\mathrm{b}$ should be equaled to 0 , and then

$$
\begin{gathered}
\mathrm{a} \sum \mathrm{t}_{\mathrm{i}}{ }^{2}+\mathrm{b} \sum \mathrm{t}_{\mathrm{i}}=\sum \mathrm{p}_{\mathrm{i}} \mathrm{t}_{\mathrm{i}} \\
\mathrm{a} \sum \mathrm{t}_{\mathrm{i}}+18 \mathrm{~b}=\sum \mathrm{p}_{\mathrm{i}}, \mathrm{i}=1-18
\end{gathered}
$$

in that formula, all the data are showed in the table.2: the results are $a=0.0218266$ and $b=-0.584618$. The function relationship of the saturated vapor of $\mathrm{NH}_{3}$ and air pressure:

$$
\mathrm{p}=0.0218266 \mathrm{t}+0.584618
$$

, it derives $\Delta \mathrm{p}=0.0218266 \Delta \mathrm{t}$ which means if the saturated vapor of $\mathrm{NH}_{3}$ rises $10^{\circ} \mathrm{C}$, the air pressure will rise $0.218266 \mathrm{Mpa}$. The mean square error by using least square method is:

$$
\mathrm{M}^{1 / 2}=0.7080906 \mathrm{Mpa}
$$

Table2. the result data from the above formula

\begin{tabular}{|l|l|l|l|l|}
\hline & $\mathrm{t}_{\mathrm{i}}$ & $\mathrm{t}_{\mathrm{i}}{ }^{2}$ & $\mathrm{p}_{\mathrm{i}}$ & $\mathrm{p}_{\mathrm{i}} \mathrm{t}_{\mathrm{i}}$ \\
\hline & -35 & 1225 & 0.09329 & -3.26515 \\
& -30 & 900 & 0.11955 & -3.5865 \\
& -25 & 625 & 0.15161 & -3.79025 \\
& -20 & 400 & 0.19022 & -3.8044 \\
& -15 & 225 & 0.23631 & -3.54465 \\
& -10 & 100 & 0.29085 & -2.9085 \\
& -5 & 25 & 0.35486 & -1.7743 \\
& 0 & 0 & 0.42944 & 0 \\
& 5 & 25 & 0.51574 & 2.5787 \\
& 10 & 100 & 0.61495 & 6.1495 \\
& 15 & 225 & 0.72831 & 10.92465 \\
& 20 & 400 & 0.85712 & 17.1424 \\
& 25 & 625 & 1.00273 & 25.06825 \\
& 30 & 900 & 1.16650 & 34.995 \\
& 35 & 1225 & 1.34989 & 47.24615 \\
& 40 & 1600 & 1.55435 & 62.174 \\
& 45 & 2025 & 1.78138 & 80.1621 \\
& 50 & 2500 & 2.03262 & 101.631 \\
\hline$\sum$ & 135 & 13125 & 13.46972 & 365.398 \\
\hline
\end{tabular}

\section{The structure of the automatic solar tracker}

The automatic solar tracker consists of two parts which are the servo system and adjusting mechanism system. The following diagram shows the details of these two parts. 


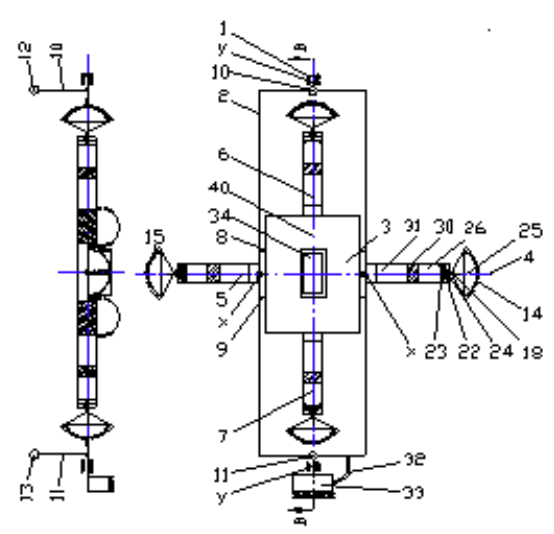

Figure1.The structure of the automatic solar tracker

\subsection{Adjusting mechanism system}

The adjusting mechanism system is the supporter and executive component of the automatic solar tracker. There are $\mathrm{x}-\mathrm{x}$ and $\mathrm{y}-\mathrm{y}$ half shafts which are mutually perpendicular and coplanar symmetric on the two symmetry axis in the rectangular frame2. And at the same time, $y-y$ half shaft is connected with basel which can relative rotation. The platform 3 can relative rotation to the frame2, so as the frame 2 can relative rotation to the frame1.The gas cylinder 30 built on the coaxial overhanging rod4 and rod5.The two ends of the axis40 are symmetry to the overhanging rod6 and $\operatorname{rod} 7$ which are set up on the platform3. A pair of symmetric u-shaped frame 8 and frame 9 set up on the frame2. And the upright tubes which are 10 and 11 perpendicular above the plane which the concurrent point between the frame 2 and the half shaft $y-y$. The around half shaft $y-y$ is built on the top of the upright tube which can turn balance block12 and 13.

\subsection{The servo system}

The four same servo systems should be set up on the four overhanging rods of the half shafts $x-x$ and $y-y$. The function of servo system is working as a sensor, feedback the location of the sun, controlling and driving the adjusting mechanism to maintain the working platform 3 perpendicular to the sun. The right side servo system on the half shaft $x-x$ can be an example. A pair of concave mirrors should be set up symmetrically on the tops of the overhanging rod4 and rod5. They can adjust the sunlight in front of them into its optical focus point. There is a blackening of copper ball 18 which works as the heat collector on the optical focus point of the concave mirror. The copper ball18 is connected with heatsink 23 through the oil cylinder 30 and heat conducting bar. And at the same time, the heat conducting bar22 is connected with the adiabatic component 24 which is on the oil cylinder 30 . There are two cavities in the oil cylinder30. A suitable amount of $\mathrm{NH}_{3}$ which is the saturated steam working medium should be injected the cavity 26 to against vaporizing pressurization before the system operating. The amount of saturated vapor which inject into cylinder steam should keep two phases of gas and liquid which in the state of saturated steam in it. The soft hermetic oil conduit32 on the nozzle of oil cylinder30 is connected with the nozzle of the swing hydraulic cylinder33 which on the half shaft $y-y$. The angle of incidence between the direction of the sun and platform 3 which is the execution unit is the sense signal of servo system.

\section{Operating process of automatic solar power tracker}

The automatic solar tracker uses energy conversion among luminous energy, heat, air pressure, hydraulic pressure and mechanical energy in servo system to drive and adjust the system in order to track motive orbit of sun. The projected area on the apertures' plane of each concave mirror is zero when the direction of sunlight perpendicular to the working platform3. So the lighting coverage concave mirror should be zero. And at the same time, the position of the working platform 3 unchanged and servo system stop operating because the blacked copper ball18 which was on the optically focal point could not collect luminous energy and absorb heat. When there is an included angle between the normal of the working platform 3 and the direction of sunlight which is not perpendicular to the working platform3, at least one concave mirror is illuminated by the sunlight ${ }^{[2]}$. In order to show this problem, if the sun illuminates left skewed and above half shaft $\mathrm{x}-\mathrm{x}$, there should be some irradiated areas on the right side concave mirror14 of the tracking machine. The concave mirror absorbs solar energy on the focal point of the blacked copper ball18, and the heat transfers to the saturated steam refrigerant through heat 


\section{MATEC Web of Conferences}

conducting bar22 and fin 23 in the air chamber 26 . The saturated steam pressure increases because it absorbs heat. And then it pushes oil and gas cylinder30 to the left. Furthermore, oil pressure in the hydraulic cylinder 31 increases, the shaft in the swinging hydraulic oil cylinder33 which is through oil conduit32 and the working platform 3 can counterclockwise whose shaft was half shaft $y-y$. It is a complete tracking cycle until the working platform 3 is perpendicular to the direction of sunlight and the lighting coverage on the concave mirror14 is zero. At the same time, during the process of working platform3 turning, the hydraulic pressure increases of the hydraulic circuit in the servo system which is on the left side of half shaft $y-y$. And the air pressure increased because the piston pushed the saturated steam under the condition of the temperature and the environment is constant. Moreover, the saturated steam would be liquidation and release of heat. And the air pressure fell back until the balance of the air pressure between the left side servo system and the right side servo system ${ }^{[3]}$. In the process of adjusting and tracking, the working platform 3 moves around the half shaft $y-y$ with an angle which is same as the angle between the direction of sunlight and the normal of the working platform3 before it moved around the half shaft $y-y$.
During the process of the working platform 3 moving around, the servo system on the left side of the half shaft $\mathrm{x}-\mathrm{x}$ moved back to the original place to prepare the next tracking cycle.

\section{Conclusion}

This new kind of tracking device which uses solar energy without electric power is suitable for the areas without electrical power; the high alpine areas and so on. It is practical and has simple structure. It also can be horizontal floating installed which is suitable for horizontal floating solar water heaters, generators, dryers and so on. The working platform 3 can use solar power effectively and track sun automatically when the symmetrical angle is in the range of $+-60^{\circ}$ between the horizontal plane and the working platform 3 .

\section{References}

[1] E.Li, etc. JSE, 24, 330-333(2003)

[2] B. Wang., $S P,(1993)$

[3] X.W. , PEP, (1981) 